\title{
STUDENT REFLECTION FROM AN IT PROJECT MANAGEMENT COURSE
}

\author{
Shabnam Boparai, University of Houston-Clear Lake, sboparai@gmail.com \\ Shreeti Pandey, University of Houston-Clear Lake, shreeti_16@hotmail.com \\ Sumeet Pawar, University of Houston-Clear Lake, sumeet763@gmail.com \\ Paul Stanley, University of Houston-Clear Lake, paulstanley84@gmail.com \\ Niraj Sharma, University of Houston-Clear Lake, niraj31@gmail.com \\ Karthik Gangupalli, University of Houston-Clear Lake, karthikgv417@gmail.com \\ Mohammad A. Rob, University of Houston-Clear Lake, rob@uhcl.edu
}

\begin{abstract}
This paper highlights the structure of an IT Project Management course as well as a summary of students' opinions on course organization and testaments on what worked well and what not. The students discuss their roles in the project groups and the knowledge gained from participating in group activities. Each student was part of a group that worked on a project and presented their work on a regular basis. The emphasis was on learning by doing, and the instructor provided feedback at regular intervals to ensure the students were incorporating the IT Project Management principles learnt in the classroom. The course provided a good mix of theoretical knowledge as well as hands-on experience. The students felt confident of their IT Project Management skills by the end of the course. The students additionally learnt to present their work to an audience, answer questions and receive feedback. The team projects and presentations helped students hone their interpersonal and communication skills.
\end{abstract}

Keywords: IT Project Management, Microsoft Project, Interpersonal skills, Collaborative learning, Work Breakdown Structure, Gantt Charts, Oral Communication, Status Reports.

\section{INTRODUCTION}

The importance of learning IT Project Management skills for Management Information Systems (MIS) students cannot be emphasized enough. A study conducted by Jacobson and Armstrong [2000] found Project Management skills to be the most sought after expertise by employers. This is probably the primary reason for the popularity of the IT Project Management course to the graduate MIS students. This paper highlights the structure of an IT Project Management course as well as a summary of the students' opinions on course organization and testaments on what worked well. The majority of the students taking the course had previously completed the System Analysis and Design course, which is designed as a foundation course for the IT Project Management course.

For the purpose of teaching this course the class was divided into groups of 5-6 students, with each group requiring to work on a case project. The instructor encouraged collaborating with an organization to undertake a live project. The idea was that through receiving classroom instruction on the theories of Project Management and then applying those to create a prototype would help students gain hands-on experience in the application of Project Management theories [3, 5, 6, 7, 11, 12, 17]. Since Project Management is the practice of managing projects through their life, this was considered an important part of the course [14]. Additionally, students would benefit by working in teams, since they would learn to work together and communicate effectively. This is an important part of the course structure, since interpersonal and communication skills are considered important factors to succeed in the workplace $[2,4,10,15]$. At regular intervals students presented their work-progress to the class and shared their experiences and learning's. Feedback was solicited from other students and this lead to a collaborative learning process, effective in reinforcing classroom learning [16].

This paper presents learning experiences from a student-group who worked on a particular case project during the semester. First we discuss the course organization, then we present the group project activities, and finally we present the particular case study. 


\section{Issues in Information Systems}

Volume XII, No. 2, pp. 30-39, 2011

\section{COURSE ORGANIZATION}

The IT Project Management class was taught through a combination of classroom lecture, group project execution, and project presentations. Most classroom times were divided into two halves - the first half was a lecture, and the second half was the project presentation. A schedule of presentation for all student groups was created at the beginning of the semester. This helped students plan their project execution activities. Towards the end of some classes, students were given time to discuss their group projects. During the class, feedback was solicited from students on the lectures and presentations. Students were welcome to ask questions during the lecture, as the instructor encouraged student participation.

A textbook [13] was assigned for the course and each class entailed discussions on the topics of particular chapters in the book. The professor encouraged discussion of real world examples to elaborate on the theories of IT Project Management. These topics were further tied into the group project activities. The project execution resulted creation of a large number documents by each group that are typically required to manage a project. Refer to Table-1.

\begin{tabular}{|l|l|c|}
\hline \multicolumn{1}{|l|}{ Process } & \multicolumn{1}{|c|}{ Documentation } & Presentation \\
\hline Initiating & Project Charter & \\
\hline Planning & Scope Statement & \\
& Work Breakdown Structure & \\
& Project Organization Structure & \\
& Responsibility Assignment Matrix & \\
& Activity Sequencing - PERT Diagram & \\
& Activity Duration - Gantt Chart & \\
& Schedule - Gantt Chart & \\
& Resource Listing & \\
& Cost Estimation & \\
& Cost Budgeting & \multirow{2}{*}{ Presentation } \\
\hline Executing & $\begin{array}{l}\text { Steps of Quality Assurance/Improvement } \\
\text { Bi-weekly Progress Report }\end{array}$ & \\
\hline Controlling & $\begin{array}{l}\text { Report changes to scope, schedule, cost, quality, people } \\
\text { Make adjustments to schedule - Gantt Chart Update }\end{array}$ & Presentation \\
\hline Closing & Final report on the project (Success, failure, lesson learned) & Presentation \\
\hline
\end{tabular}

Table-1: An overview of Project Documentations and Presentations required for the Course

Credit in the course was received by active participation in group projects and presentations, and submission of research papers and answers to textbook questions. There were two exams, a mid-term exam and a final. The midterm exam comprised of short answer questions based on the textbook chapters discussed in class. The final was a research paper, the outcome of which you are currently reading.

\section{Group Projects}

In the first class period, the students were divided into groups consisting of approximately 5 to 6 students. Each group had a mixture of students with work experience and no experience at all. Within each group, students assigned roles by themselves according to their past work experience, aptitude, and career interests. Specifically each group assigned a Project Manager, Systems Architect, Business Analyst, Database Analyst, and programmers. Students were expected to meet regularly to assign and discuss project work. Methods of communication were decided among group members early on in the project.

The groups were allowed to select projects on their own, but they were encouraged to select live projects, i.e. projects that would meet a need or replace current systems for an organization. The students selected a wide variety of projects, from building online booking systems for restaurants, to building online billing systems for healthcare companies. Our group decided to make an online student bulletin for the Student Services Office. The project was 


\section{Issues in Information Systems}

Volume XII, No. 2, pp. 30-39, 2011

chosen to replace the current system of physical bulletin boards. The idea was that an online system would be more efficient, and, if promoted appropriately, would reach a wider audience of students.

Project execution by the students groups followed textbook topics discussed in class. This means that an explanation of each stage of IT Project Management preceded the execution of that phase by the students in the project. So students had a clear understanding of how to proceed on the projects. The instructor presented guidance throughout the execution of projects by participating in student meetings in the classroom, and by providing feedback to project presentations. The instructor was also available, via email and during designated office hours, to answer ad-hoc questions that arose during project execution.

\section{Group Presentations}

The group presentations were divided into phases according to established IT Project Management processes Initiating, Planning, Executing, Monitoring and Controlling, and lastly closing. Refer to Table-1. There were presentations for each phase of IT Project Management life cycle. During each phase, documentations were created by the group for project management and project execution. These documents were included in the presentations to demonstrate the decision making process and progress made on the project respectively.

At each presentation, the student groups presented the documents that were produced during that particular phase of project management. The formats for most documents were borrowed from the textbook - changes were made to suit the project at hand. Some of the documents presented include -Project Charter, Work Breakdown Structure, Microsoft Project file including Gantt Charts, Status Reports, Surveys, and Test Document.

Each student in a group participated in the group presentations and presented the portion of work conducted by them. At the end, and even during the presentations, the instructor and students were given time to ask questions regarding the presentation. Finally at the end, the instructor gave feedback, which included appreciation of parts of the project that were executed well, mentioning things that were missed, and opportunities for improvement.

\section{THE CASE OF ONLINE STUDENT BULLETIN BOARD}

Before discussing ideas for possible projects the team decided on each team members' roles. We discussed our career interests and past work experience. Team members were able to accept roles that matched their skills and interests and we have selected a project manager, an assistant project manager, a systems analyst, a systems architect, a database analyst, and a programmer. A day and time was fixed for weekly meetings, and a format was developed for status reports. Team members agreed to be available through emails for updates between scheduled meetings and on phone in case of emergencies.

The group decided to build an online Student Bulletin for the Student Services Office. The project was selected because it would replace, or complement, the current physical bulletin board that is used to post flyers with information to buy or sell various items as well as other information. The Student Services Office maintains a physical bulletin board in one location of the campus, which is not very convenient for students all across the campus. Furthermore, to post an advertisement, students must take the flyer to the Student Life office to get stamped before it could be posted on the board. Alternately they could fill out a form available in the office and the form would then be posted on the bulletin board.

Apart from the complexity of access and approval process, there is a significant problem of finding appropriate information. Most of the times, the bulletin board would be cluttered with numerous advertisements - finding appropriate information means scanning through a lot of flyers to get to the right information. Refer to figure 1 for a picture of the current bulletin board. Older flyers would get hidden behind newer ones. Also, there is no organization of advertisements according to categories. 


\section{Issues in Information Systems}

Volume XII, No. 2, pp. 30-39, 2011

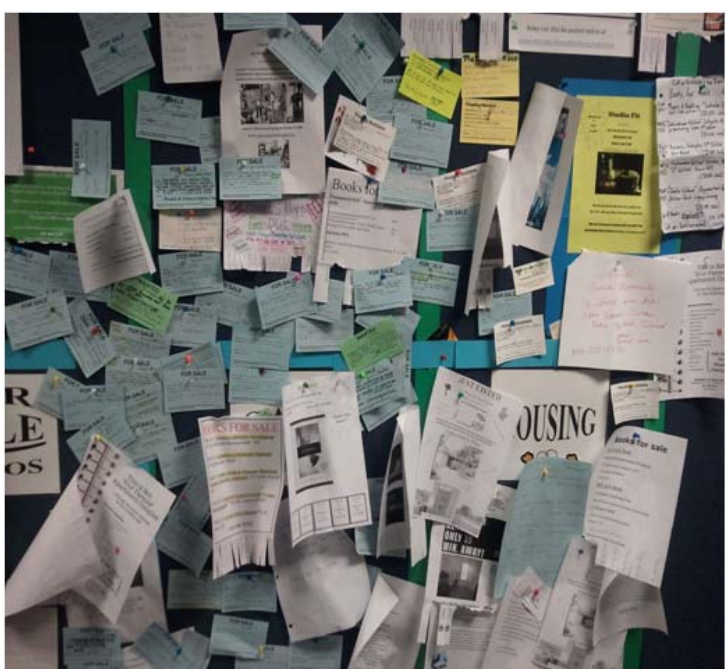

Figure 1: Existing Student Life Bulletin Board

After discussing the problem with the instructor, the team decided to develop an online student bulletin board. The first step of the project was a needs assessment and was done using a questionnaire to interview the Director of Student Life. The questionnaire was developed during one of the team meetings. Our Business Analyst was elected to schedule and conduct interviews with the Student Life office. After the meeting, the team was briefed about the information gathered from the interview. The team then begun to sketch out the important features of the online Student Bulletin Board and how it would work. Please refer to Appendix A for the scope statement of the project, which outlines the project- and product-related outcomes. The important idea was to have a website where students could log in and post advertisements, for example, a used car or used furniture for sale. Other students could log in and search for the information. Over the course of the semester, and through multiple meetings, the web-based system was built and tested. Please refer to figure 2 for a screen shot of the website listing all project- and productrelated documents at instructor's website (http://mis.uhcl.edu/rob/Course/PM/Projects/Projects.htm).

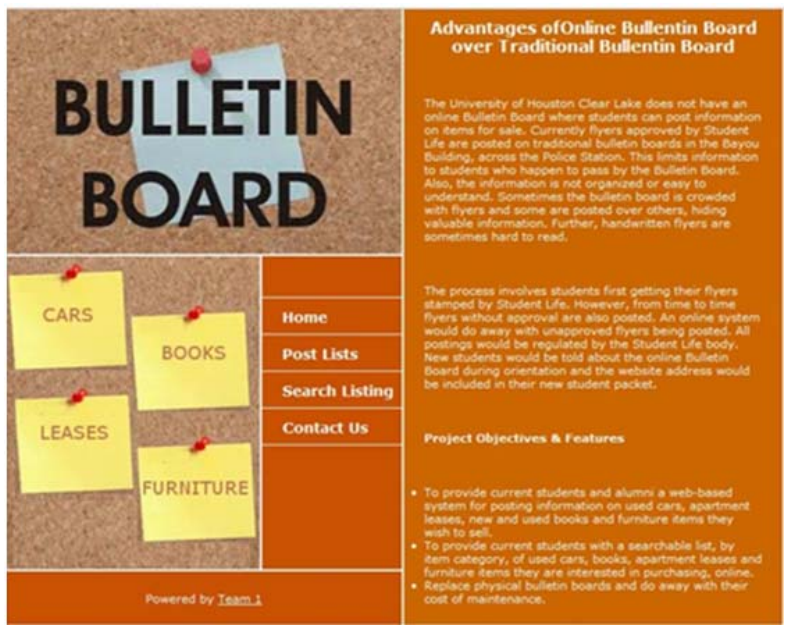

Figure 2: Web-based Student Bulletin System

Note during the course of our study, emphasis was placed on the project management activities rather than developing a full-blown system and thus only a prototype of the system was developed while focus was placed 
mainly on developing all project-related documents. In every three weeks, we had to present the updated Gantt chart along with other documents that we had to make in managing the project activities. Please refer to Figure 3. Figure 4 shows a list of documents developed during the course of our study as shown on instructor's website. By going through the activities of developing the documentations as well as the online bulletin board system, we have learned the process of project management while developing an information system.

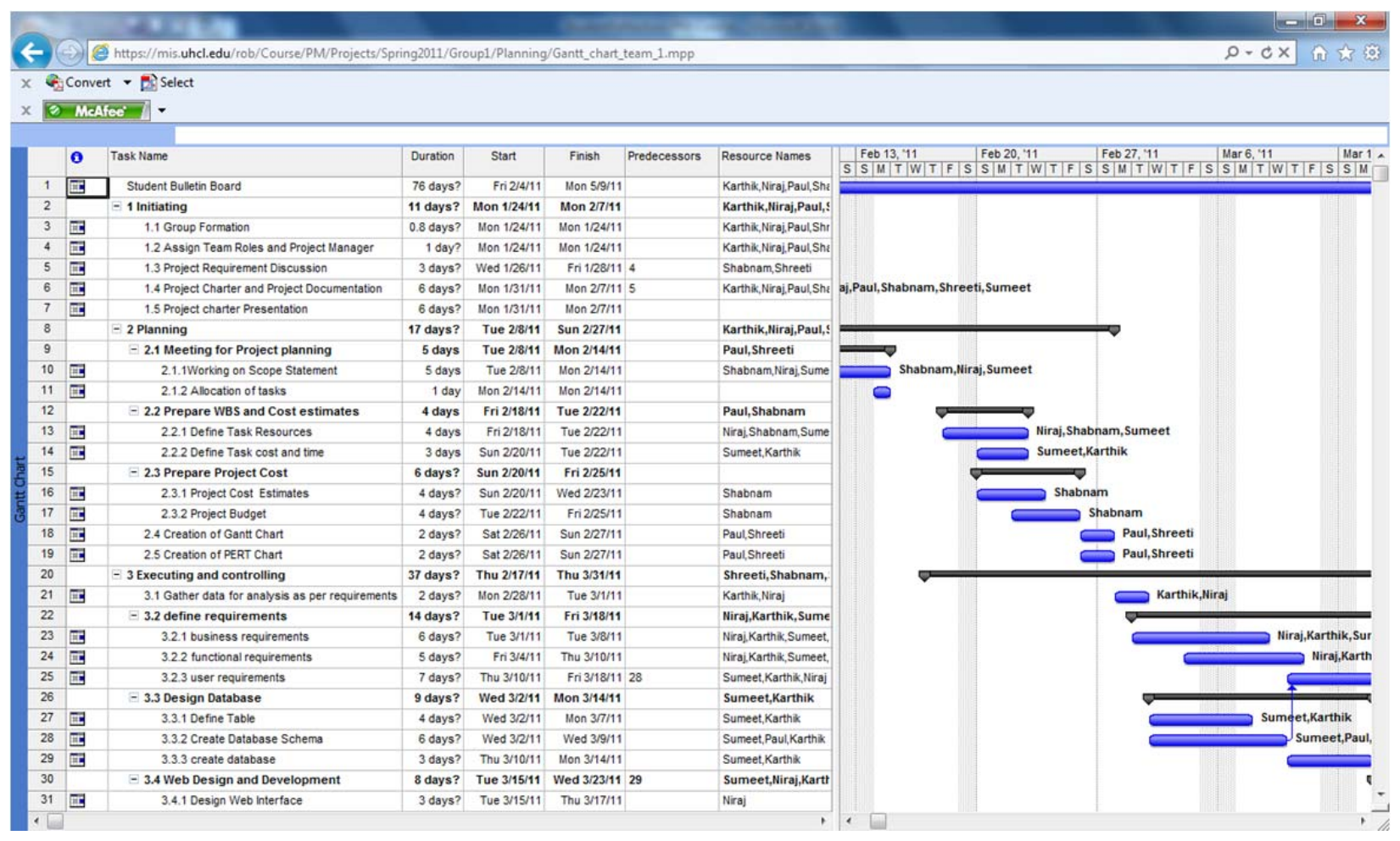

Figure 3: Gantt chart for managing the development of Student Bulletin Board 


\section{Issues in Information Systems}

Volume XII, No. 2, pp. 30-39, 2011

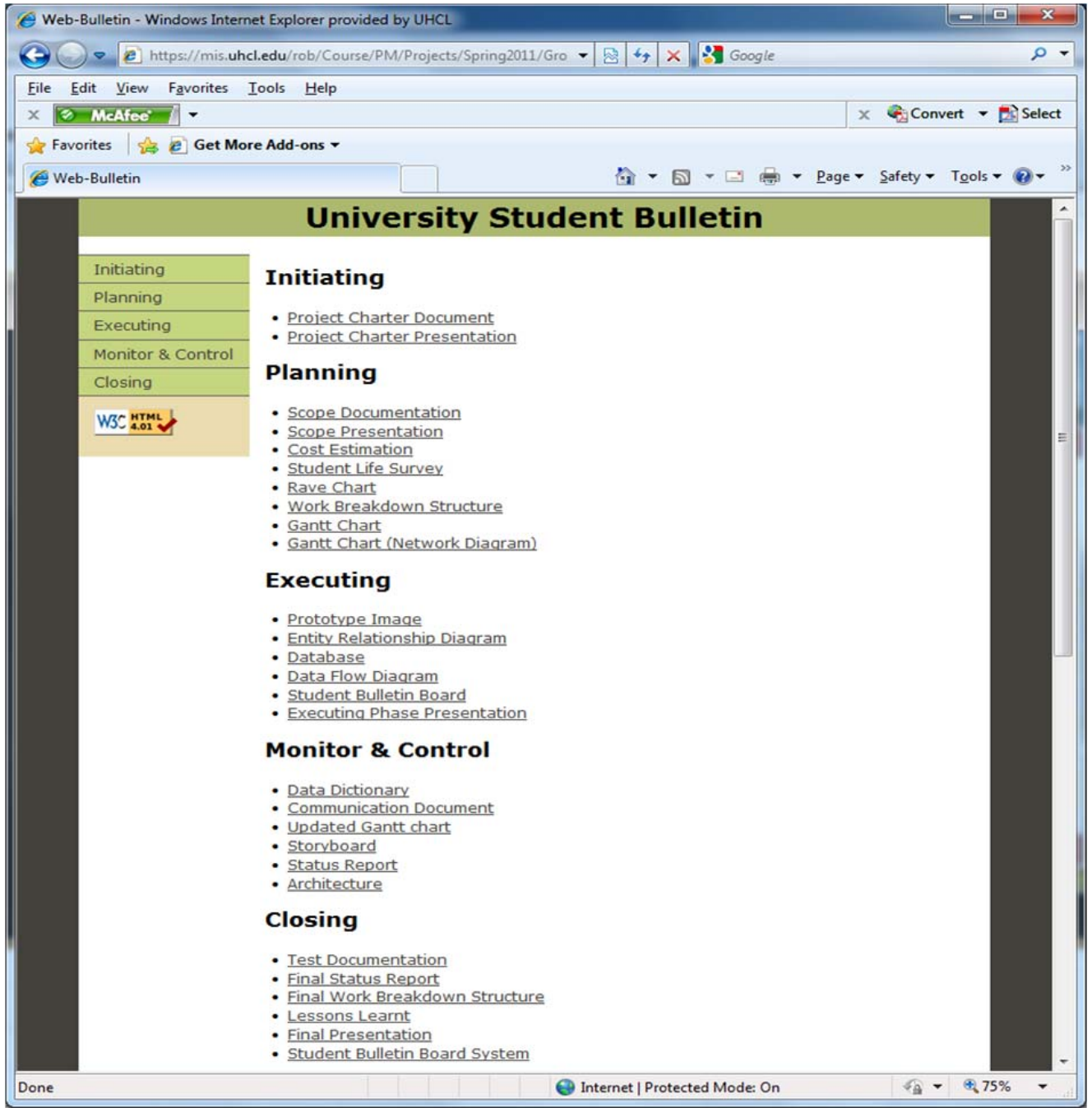

Figure 4: Documentation by Process Group as Listed \& Posted in the Website: http://mis.uhcl.edu/rob/Course/PM/Projects/Spring2011/Group1/Web-Bulletin.html

\section{DISCUSSION}

The class provided a good mix of theoretical as well as practical learning of IT Project Management processes. The group felt that IT Project Management was an important course to take irrespective of the career choices the team members made after graduation. Additionally, the team thought taking the course would enhance their resume by adding exposure to a management course. The structure of the course allowed students to practice the processes learnt through a group project.

The method of forming groups allowed students to interact and work with students other than their friends. Also, the mix of students with work experience and those without ensured each group would have varied opinions and working styles. The team agreed this helped them work harder at their communication skills, some of us felt we learnt to be more articulate and assertive. Working with new people also meant going beyond the comfort zone some of us have with our friends at the university.

When the team discussed the factors that helped us work effectively and efficiently for the project, the majority of us agreed it was due to the open and regular communication between team members. Regular updates on tasks helped 


\section{Issues in Information Systems}

Volume XII, No. 2, pp. 30-39, 2011

the team plan and reassign responsibilities. Additionally, respect and appreciation for team members' work motivated everybody to work hard.

The team members felt that the process of preparing, presenting, answering questions, and receiving feedback helped them gain skills essential to succeed on the job. Additionally we learnt new software; the project required using Microsoft Project to maintain updated work schedules. Finally, some members expressed an improvement in their programming skills due to the project. Since the online system was built using ASP.Net and SQL Server, the students who built the system noted an improvement in their understanding and implementation of the technologies. Appendix B displays the lessons learned document that was presented towards the closing of the project.

\section{CONCLUSION}

The group project provided an opportunity for students to practice, and improve, their presentation skills, as well as enhanced their programming skills learnt in previous courses; this phenomenon was also observed by Baker-Eveleth et al. [2005] in their studies. Finally, another very important advantage of doing projects is the opportunity to partner with organizations, build a relationship between the University and the organization, for continued live project opportunities for students, as evidenced in California State Polytechnic University, Pomona in Southern California $[11,2,10]$.

Overall the team members felt they benefited by taking the IT Project Management course. An extension of this course could be done to provide an online version, where virtual teams would work together using technology to complete IT projects. This has been done with some success in other universities [8, 10].

\section{REFERENCES}

1. Baker-Eveleth, L., Stone, R. W., \& Pendegraft, N. (2005). The Role of Information Systems Class Projects in Developing Programming Skills and Self-Efficacy. Journal of Informatics Education Research, 7(2), 91-118.

2. Chan, S. (2003). A Team Project Approach to Teaching E-Commerce Development. Journal of Informatics Education Research, 5(2), 55-68.

3. De los Rios, I., Ortiz, I., \& Diaz-Puente, J. M. (2008). Project Management Teaching in Engineering Higher Education: A New Perspective for Developing Competencies. Selected Proceedings from the $12^{\text {th }}$ International Congress on Project Engineering, 418-427.

4. Jacobson, C. M., \& Armstrong, R. D., (2000). Information Systems Professionals for the New Millennium: What Employers Want. Journal of Informatics Education Research, 2(1), 41-48.

5. Mackrell, D. (2009). The Work Readiness of Master of Information Systems International Students at an Australian University: A Pilot Study. Issues in Informing Science and Information Technology, 6, 179-192.

6. Passerini, K. (2006). Working with Real Customers: Examples from Project-Based MIS Courses. Journal of Informatics Education Research, 8(1), 77-102.

7. Rob, M. A. (2003). The Management of Teaching IT Project Management. Journal of Informatics Education Research, 5(2), 15-28.

8. Sarker, S., Sahay, S., \& Lau, F. (2002). Teaching Information Systems Development Using "Virtual Team" Projects. Journal of Informatics Education Research, 4(1), 35-46.

9. Schwartz, R.B., \& Schwartz, B. N. (2006). Bringing IR Professionals and Graduate Students Together: A Capstone Course in an IT Program. Journal of Informatics Education Research, 8(1),103-122.

10. Small, R. V., (2004). Building Collaboration through Technology. Journal of Informatics Education Research,6(2), 61-68.

11. Soe, L., \& Hwang, D. (2001). A Student Team Project for Effective Use of Internet Technologies by a Manufacturing Company. Journal of Informatics Education Research, 3(1), 43-52.

12. Steenkamp, A. L., White, T., \& Kakish, K. (2002). A Project-Centered Approach to Teaching Information Technology and System Architectures. Journal of Informatics Education Research, 4(2), 1-14. 


\section{Issues in Information Systems}

Volume XII, No. 2, pp. 30-39, 2011

13. Schawlbe, K. (2009) Information Technology Project Management, Sixth Edition, Course Technology/Cengage Learning: Independence, KY.

14. Tatnall, A., \& Reyes, G. (2005). Teaching IT Project Management to Postgraduate Business Students: A Practical Approach. Journal of Information Technology Education, 4, 153-166.

15. Thomas, T., \& de Villiers, C. (2001). Teaching IS Soft Skills to a Diverse Student Population: Case Studies using JAD and Co-operative Learning Techniques. Journal of Informatics Education Research, 3(2), 39-52.

16. Yadin, A. (2010). Improving Learning Habits for Generation Y Students. Journal of Informatics Education Research.

17. Zapata, C. M., \& Awad-Aubad, G. (2007). Requirements Game: Teaching Software Project Management. CLEI Electronic Journal, 10(1) 


\section{Issues in Information Systems}

Volume XII, No. 2, pp. 30-39, 2011

Appendix A: The Scope Statement for the University Bulletin Board

\section{SCOPE STATEMENT}

Project Title: University Student Bulletins

\section{Project Justification}

Date: $2 / 20 / 2011$

Currently University of Houston-Clear Lake (UHCL) doesn't have an online Bulletin Board where students can post information on items for sale. There is a physical bulletin at a single location, with limited space, that is difficult to search and time consuming to maintain. An online system would do away with the shortcomings of a physical bulletin, and make searching for information a better experience for UHCL students.

\section{Product Characteristics and Requirements}

The web-based bulletin would provide students a web interface where they can post listings using a standardized form. A database would make listings searchable for students looking for information. Additionally features like automatic registration with UHCL email id, and expiration dates on postings would make the system low maintenance.

\section{Project Management Related Deliverables}

The project management deliverables of the project include - a business case based on needs assessment, a project charter, statement of scope, work breakdown structure (WBS), scheduling documents, cost estimation documents, a document outlining the risks associated with the project, status reports, the final project presentation and report, and a lessons learned report.

\section{Product Related Deliverables}

The product deliverables include building a prototype of the online student bulletin. The prototype will include the website complete with web interface and database development. Additionally any training material and system documentation needed to support and maintain the system will be provided.

\section{Success Criteria}

The success of the project will largely depend on the website being completed on schedule and within budget. Furthermore an intuitive and user friendly website would determine how frequently students use the system and favor it over the traditional bulletin board. Finally, a high adoption rate would guarantee large number of postings and contribute to the success of the project. 


\section{Issues in Information Systems}

Volume XII, No. 2, pp. 30-39, 2011

Appendix B: Lessons learnt in managing the Student Bulletin Board project

\section{Lessons Learnt Report}

Project Title: University Student Bulletins

Date: $4 / 14 / 2011$

Did the project meet scope, time and cost goals?

Yes, the project met its scope, time and cost goals. The project was finished within budget and on time. The primary scope of the project was met - an online bulletin board for the students of UHCL. The final deliverable - demo of the web based system to Student Life is remaining. The feedback from Student Life thus far has been positive and supportive. They see the value in UHCL having a web based bulletin and hope it will be popular with students and staff members as a means to look for used furniture, cars and books.

\section{What worked well, what didn't work well?}

The team worked well together by communicating regularly and effectively. Team members were supportive and appreciate of the work of fellow team members. This was helpful in maintaining the morale of the team and each member took ownership of their duties and responsibilities. We had weekly meetings to provide updates and delegate work. This helped the communication flow and better allocation of resources for the project. Team members would provide an update on their progress, any changes were noted, and if required additional resources were allocated.

\section{Were the projects goals achieved?}

Yes, the goals of the project were achieved the web based bulletin board is ready, and has been tested. A demo of the system to Student Life has been scheduled.

\section{Were there any unanticipated changes? If yes, how did the team adapt?}

Some phases of the project took longer than expected and resources were reassigned in order to complete the project on schedule. Specifically in the executing phase some team members had to take on additional roles to meet the deadlines and stay on schedule.

\section{What was the main success criteria listed in the project scope statement?}

The main success criteria listed in the project scope statement was high adoption rates for the web based student bulletin. High adoption of the system by students in UHCL is dependent on how the website is promoted on campus by Student Life.

\section{What are the main lessons learnt?}

The main lessons learnt are that regular and open communication helps keep team members informed of progress. Also, team members' appreciation and support for each other leads to a cohesive and well functioning team. Finally, regular updates should be made to stakeholders, so any discrepancies in project goals can be addressed in a timely manner. This is important so that changes can be made in time and resources are not wasted on unwanted work. 